\title{
Ratiometric fluorescence signalling of fluoride ions by an amidophthalimide derivative
}

\author{
MOLOY SARKAR, RAGHAVENDRA YELLAMPALLI, ${ }^{+}$BHASWATI BHATTACHARYA, \\ RAVI KUMAR KANAPARTHI and ANUNAY SAMANTA* \\ School of Chemistry, University of Hyderabad, Hyderabad 500046 \\ ${ }^{+}$Present address: Training School, Bhabha Atomic Research Centre, Trombay, Mumbai 400085 \\ e-mail: assc@uohyd.ernet.in
}

\begin{abstract}
Fluorescence behaviour of 4-benzoylamido-N-methylphthalimide (1), designed and developed for selective detection of fluoride ions, is reported. 1 displays $\mathrm{F}^{-}$-induced colour change that allows its detection with the naked eye. The $\mathrm{F}^{-}$specificity of the sensor system is evident from the fact that unlike $\mathrm{F}^{-}$, other halides do not affect the absorption characteristics of $\mathbf{1}$. Apart from the colorimetric response, the fluorescence output of $\mathbf{1}$ is also modulated by $\mathrm{F}^{-}$in a manner that permits ratiometric fluorescence signalling of $\mathrm{F}^{-}$as well. It is found that the system can detect $\mathrm{F}^{-}$in the concentration range of 10$60 \mu \mathrm{M}$. The results of the experiments and theoretical calculations unambiguously suggest that the changes of the electronic absorption and fluorescence behaviour of $\mathbf{1}$, which have been exploited for signalling purpose, are due to $\mathrm{F}^{-}$-induced deprotonation of the 4-amido moiety of the sensor system.
\end{abstract}

Keywords. Chemosensor; ratiometric fluorescence signalling; fluoride ion; proton transfer; density functional calculation.

\section{Introduction}

There is a great deal of interest in the design and development of molecular systems, which are capable of sensing various biologically and chemically important chemical species. ${ }^{1-21}$ These chemosensors are molecular systems that transform chemical information, such as recognition of a chemical species and/or measurement of its concentration, into an analytically useful signal. Significant work has already been done to obtain a specific chemosensor, which upon addition of the target chemical species, responds by displaying changes in one or several of its measurable properties. Changes in the optical absorption and fluorescence output in response to a target species have been exploited in the development of optical chemosensors for the recognition of positively charged species such as alkaline, alkaline earth and transition metal ions, various anions and neutral species such as saccharides, peptides, oxygen, carbon dioxide etc. ${ }^{3-16}$ There are a number of contemporary review articles available on this topic. ${ }^{1-16}$

Recognition of fluoride ions has been a topic of great interest mainly because of its beneficial (e.g. treatment of osteoporosis) $)^{22,23}$ and detrimental (e.g.

*For correspondence fluorosis) ${ }^{24}$ roles. $^{3-9}$ Commonly, molecular systems containing polarized $\mathrm{N}-\mathrm{H}$ fragments, which behave as hydrogen-bond donors towards anions, are used as receptors for recognition and sensing of $\mathrm{F}^{-}$in aprotic solvents. ${ }^{9}$ The stability of the receptor-anion complex is strictly related to the acidic nature of the receptor and the basic nature of anions. There can be two limiting situations: In one case, the receptoranion complex is stabilized by H-bonding interaction. ${ }^{9}$ In the second one, if the receptor is such that the $\mathrm{N}-\mathrm{H}$ fragment is sufficiently polarized, the acidity of the $\mathrm{N}-\mathrm{H}$ proton is so enhanced that a sufficiently basic anion can completely abstract this labile proton instead of hydrogen-bonding interaction. ${ }^{9}$ This deprotonation event is typically observed for highly basic anions like fluoride ions due to the formation of a stable $\left[\mathrm{HF}_{2}\right]^{-}$self-complex. ${ }^{9}$ The higher basicity of the fluoride ion compared to the other halides is commonly exploited for the purpose of specific recognition of $\mathrm{F}^{-}$. Since both H-bonding and proton-transfer mechanisms often give rise to very similar output signals of the sensor, a detailed study is necessary for determination of the actual mechanism of signalling.

Compared to the large number of chemosensors that have been developed for various metal ions, ${ }^{10-21}$ relatively few chemosensors are reported in the lite- 
rature for selective sensing of fluoride ions. ${ }^{25-38}$ However, for most of the reported fluoride sensors, the binding of the anion causes quenching of the fluorescence intensity. ${ }^{34,35}$ Only a few sensors show guest-induced enhancement of the fluorescence intensity ${ }^{36,37}$ In this context, it is important to note that single wavelength intensity-based fluoresensors suffer from a number of poorly quantified factors due to the fluctuation of the excitation intensity, photobleaching, dependence of the fluorescence output on the sensor concentration etc. Recent investigations have focused on developing ratiometric fluorescence sensors as they permit signal rationing and provide built-in correction for the environmental effects, intensity fluctuations etc. However, ratiometric fluorescent sensors for fluoride ions are rather limited. ${ }^{27,38}$ Taking all these aspects into consideration, we have designed and developed 1 , wherein a 4aminophthalimide fluorophore has been utilized primarily because of its high fluorescence yield, sensitivity of the fluorescence parameters on the added reagents and surrounding environment, and electron-deficient nature. ${ }^{39} \mathrm{~A}$ benzoyl moiety has been appended to the amino nitrogen of the fluorophore to make the amino hydrogen highly acidic, which, as stated above, is one of the primary design requirements for signalling fluoride ions. In this manuscript, we report the absorption and fluorescence behaviour of $\mathbf{1}$ in the absence and in presence of the halide ions. Theoretical calculations based on the density functional method have been carried out with a view to substantiating the mechanism of the signalling.

\section{Experimental}

\subsection{Synthesis of 4-(benzoylamido -N-methyl-1,8-} phthalimide (1)

4-Amino-N-methylphthalimide (100 $\mathrm{mg}, 0.57 \mathrm{mmol})$ (procured from Aldrich) was taken in a $50 \mathrm{ml}$ roundbottom flask and dissolved in a small amount of

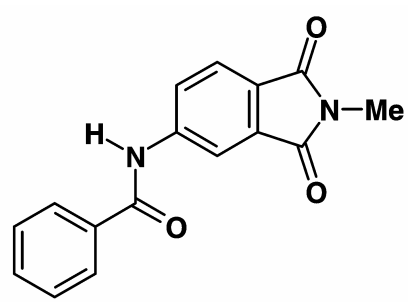

Chart 1. 4-Benzoylamido-N-methylphthalimide (1).
DCM. After addition of $0.1 \mathrm{ml}(0.86 \mathrm{mmol})$ of benzoyl chloride, the reaction mixture was magnetically stirred for about $3 \mathrm{~h}$ at $40^{\circ} \mathrm{C}$, and then filtered. The solid residue was recrystallized from acetonitrile to obtain 1 as a white solid compound. Yield $63 \%$.

1 was characterized by the following analytical data:

${ }^{1} \mathrm{H}$ NMR $\left(400 \mathrm{MHz}\right.$, DMSO- $\left.d_{6}\right): \delta 10.76(s, 1 \mathrm{H})$, $8.34(s, 1 \mathrm{H}), 8.12(d, J \approx 8.0 \mathrm{~Hz}, 1 \mathrm{H}), 7.96(d$, $J \approx 8.0 \mathrm{~Hz}, 2 \mathrm{H}), 7.84(d, J \approx 8.0 \mathrm{~Hz}, 1 \mathrm{H}), 7.55-7.62$ $(m, 3 \mathrm{H}), 4.02(s, 3 \mathrm{H})$.

LC-MS: $m / z 299\left[(M+1)+\mathrm{H}_{2} \mathrm{O}\right]^{+}$.

\subsection{Instrumentation and methods}

Absorption and steady-state fluorescence spectra were recorded on a UV-Vis spectrophotometer (Cary 100, Varian) and a spectrofluorimeter (FluoroLog-3, Jobin Yvon) respectively. The fluorescence spectra were corrected for instrumental response. Typically, aliquots of a freshly prepared tetrabutylammonium salt solution of the required anion $\left(\mathrm{F}^{-}\right.$, $\mathrm{Cl}^{-}, \mathrm{Br}^{-}, \mathrm{I}^{-}$) were added for UV-Vis absorption and fluorescence titration. Time-resolved fluorescence measurements were carried out using a time-correlated single-photon counting (TCSPC) spectrometer $(5000$, IBH $) . \quad A$ diode laser $\left(\lambda_{\text {exc }}=374 \mathrm{~nm}\right.$, $\mathrm{FWHM}=65 \mathrm{ps}$ ) was used as the excitation source and an MCP photomultiplier (Hamamatsu R3809U50) as the detector. The lamp profile was recorded by placing a scatterer (dilute solution of Ludox in water) in place of the sample. Decay curves were analysed by nonlinear least-squares iteration procedure using IBH DAS6 (Version 2.2) decay analysis software. The ${ }^{1} \mathrm{H}$ NMR spectra were recorded on a Bruker AVANCE 400 NMR spectrometer at ambient temperature using tetramethylsilane (TMS) as an internal standard. LC mass were recorded on a Shimadzu LCMS-2010A mass spectrometer. The dipole moments of 4-aminophthalimide (AP), 1 and the optimised geometries of the molecular complexes of $\mathbf{1}$ with fluoride and chloride ions were obtained by density functional calculations at the B3LYP/STO$3 \mathrm{G}$ level using the Gaussian 03 series of programs. ${ }^{40}$

\section{Results and discussion}

\subsection{Absorption and fluorescence behaviour of $\mathbf{1}$}

4-Aminophthalimide (AP) exhibits a broad intramolecular charge transfer absorption band as the 
lowest energy electronic transition. The absorption maximum is observed between 350 and $370 \mathrm{~nm}$ depending on the polarity of the medium. ${ }^{39} 1$ also exhibits a broad absorption band (figure 1). However, the absorption maximum of 1 appears at $330 \mathrm{~nm}$ irrespective of the polarity of the medium. The blueshift of the absorption maximum of 1 relative to that of AP and insensitivity of the peak position on the solvent polarity suggests that the ground state dipole moment of 1 is significantly lower than that of AP. Indeed, DFT calculations reveal that the groundstate dipole moment of $\mathbf{1}$ is only $0.92 \mathrm{D}$ as compared to $3 \cdot 11 \mathrm{D}$ for $\mathrm{AP} .^{41}$ The low dipole moment of $1 \mathrm{can}$ be rationalized taking into consideration the fact that charge separation in the AP moiety (from the 4amino nitrogen atom to the carbonyl groups) is significantly reduced on replacement of one of the amino hydrogen atoms by the electron-withdrawing $\mathrm{C}_{6} \mathrm{H}_{5} \mathrm{CO}$-group.

The fluorescence spectrum of $\mathbf{1}$ is also characterized by a structureless band (figure 1) with its maxima at $400 \mathrm{~nm}$ in tetrahydrofuran and $412 \mathrm{~nm}$ in acetonitrile. The solvent sensitivity of the fluorescence peak position suggests that the excited state of 1 is more polar than the ground state. However, the sol-

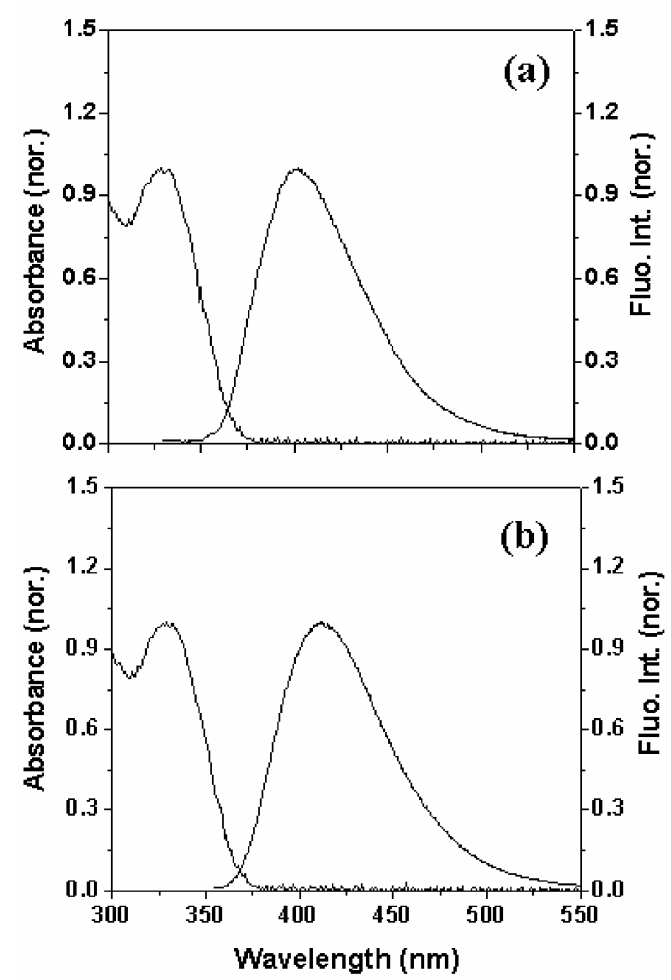

Figure 1. Absorption and emission spectra of $\mathbf{1}$ in tetrahydrofuran (a) and in acetonitrile. (b) $\lambda_{\mathrm{exc}}=350 \mathrm{~nm}$. vent sensitivity of emission, as expected, is much less pronounced compared to AP. ${ }^{39}$ The fluorescence decay behaviour (monitored at $410 \mathrm{~nm}$ in acetonitrile) of 1 is characterized by a biexponential decay (figure 2) with the decay parameters: $\tau_{1}=5.32 \mathrm{~ns}$ $(66 \%), \tau_{2}=12.9 \mathrm{~ns}(34 \%)$. Interestingly, AP exhibits single-exponential fluorescence decay with a lifetime of $14 \mathrm{~ns}$ in acetonitrile. ${ }^{39}$

\subsection{Absorption titration of $\mathbf{1}$ with halide ions}

Spectrophotometric titrations have been performed using a dilute acetonitrile solution of $\mathbf{1}$, adding small quantities of freshly prepared stock solutions of appropriate tetrabutylammonium halide salt. Specifically, to a $1.5 \times 10^{-6} \mathrm{M}$ acetonitrile solution of 1 , stock solution of tetrabutylammonium fluoride (TBAF) was added in a stepwise fashion. Upon progressive addition of TBAF, a bathochromic shift $(\approx 8 \mathrm{~nm})$ of the $330 \mathrm{~nm}$ peak is observed along with a marginal increase of the intensity of this band. Moreover, a completely new band with a maximum at $425 \mathrm{~nm}$ is also observed (figure 3). The colourless solution of 1 turns yellow in the presence of $\mathrm{F}^{-}$. The equilibrium constant for the reaction, $\mathrm{LH}+2 \mathrm{~F} \rightleftharpoons$ $\mathrm{L}+\left[\mathrm{HF}_{2}\right],{ }^{9}$ has been calculated from the measured changes of the absorbance at $425 \mathrm{~nm}$ as a function of the concentration of $\mathrm{F}^{-}$. The estimated equili-
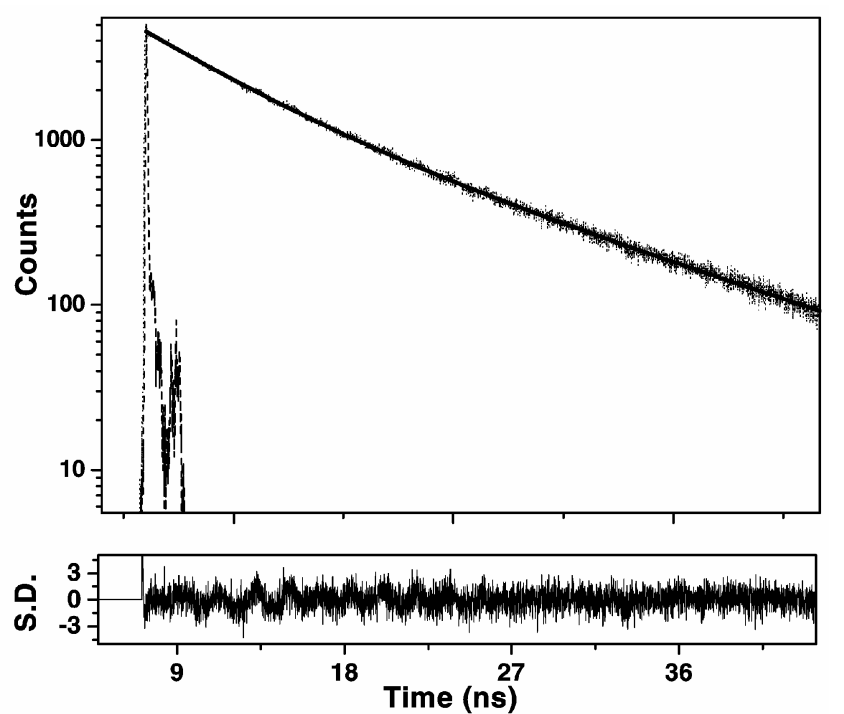

Figure 2. Fluorescence decay curves for $\mathbf{1}$ in acetonitrile. Solution is excited at $374 \mathrm{~nm}$ and emission is monitored at $412 \mathrm{~nm}$. The solid lines represent the best fit to the data. The weighted deviations are also shown below the respective decay curves. 
brium constant is found to be $9 \cdot 1 \times 10^{3}( \pm 10 \%)$. Interestingly, other halides do not show any significant change in the optical absorption behaviour of 1 even when the halide concentration is $\sim 100$ times more than that used for fluoride (figure 3). As stated earlier, the spectral change can be attributed to the formation of a hydrogen-bonded complex between 1 and $\mathrm{F}^{-}$or due to the deprotonation of the acidic amido proton by $\mathrm{F}^{-}$.

However, since similar spectral changes of 1 have been observed in the presence of stronger bases such as $\mathrm{Bu}_{4} \mathrm{NOH}$ and $\mathrm{NaH}$ and weaker bases such as $\mathrm{NEt}_{3}$ cannot induce any spectral changes, we conclude that the ground-state proton transfer reaction between the amide group of the sensor and $\mathrm{F}^{-}$is responsible for the change in the optical behaviour of 1. Essentially, this implies that new absorption at $425 \mathrm{~nm}$ is due to the anionic form of 1 .

\subsection{NMR titration of 1 with fluoride}

In order to substantiate that in the presence of $\mathrm{F}^{-}$the amido proton is abstracted from 1 leading to the formation of its anion, we have carried out a proton NMR titration as well (figure 4). It can be seen, with gradual addition of $\mathrm{F}^{-}$, that the amide $\mathrm{NH}$ proton signal, which appears at around $11 \mathrm{ppm}$ initially, gets broadened and then disappears completely for

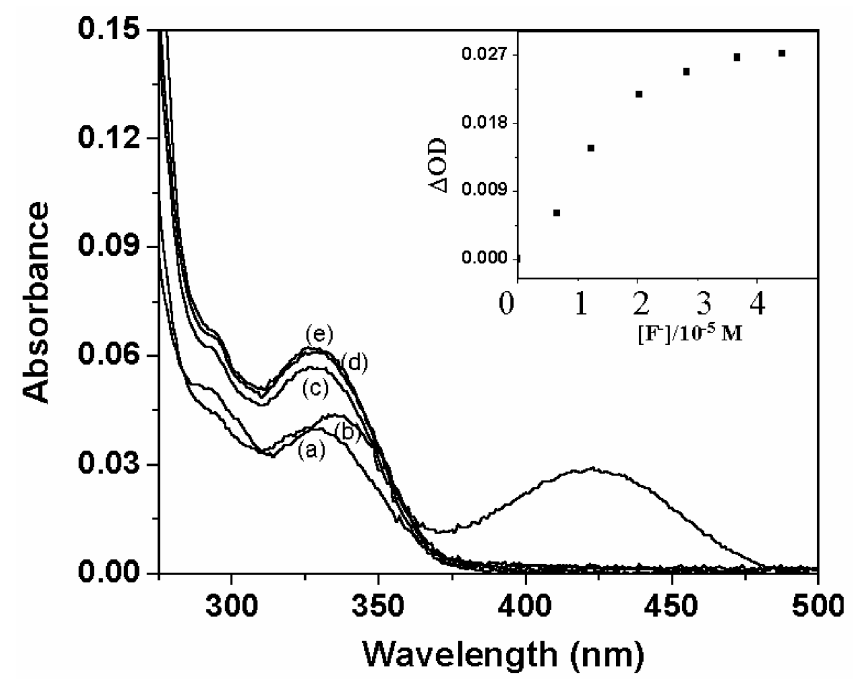

Figure 3. Effect of the halide salts on the absorbance spectra of acetonitrile solution of $1\left(1.5 \times 10^{-6} \mathrm{M}\right)$ : (a) no added salt, (b) with fluoride $\left(4.4 \times 10^{-5} \mathrm{M}\right)$, (c) with chloride $\left(4.0 \times 10^{-3} \mathrm{M}\right),(\mathrm{d})$ with bromide $\left(4.0 \times 10^{-3} \mathrm{M}\right)$ and (e) with iodide $\left(4.0 \times 10^{-3} \mathrm{M}\right)$. Inset shows the change in optical density at $425 \mathrm{~nm}$ as function of $\left[\mathrm{F}^{-}\right]$. higher concentration of $\mathrm{F}^{-}$. This observation is a typical signature of the formation of the hydrogen bond and subsequent transfer of the proton to $\mathrm{F}^{-}$.

\subsection{Fluorescence spectra titration of $\mathbf{1}$ with halides}

Upon gradual addition of TBAF to an acetonitrile solution of 1 , a significant decrease in the fluorescence intensity of the $412 \mathrm{~nm}$ band is observed along with the emergence of a new emission band centred at 570 (figure 5). ${ }^{42}$ A clear iso-emissive point is observable at $505 \mathrm{~nm}$. Upon addition of the other halides, no significant changes in the fluorescence behaviour were observed apart from quenching of the original fluorescence, presumably due to the heavy atom effect (figure 6). The changes, 'switching off' of the $412 \mathrm{~nm}$ emission band and 'switching on' of the $570 \mathrm{~nm}$ emission band, which, as we have already established, is due to proton abstraction from 1 , transfer reaction by $\mathrm{F}^{-}$leading to

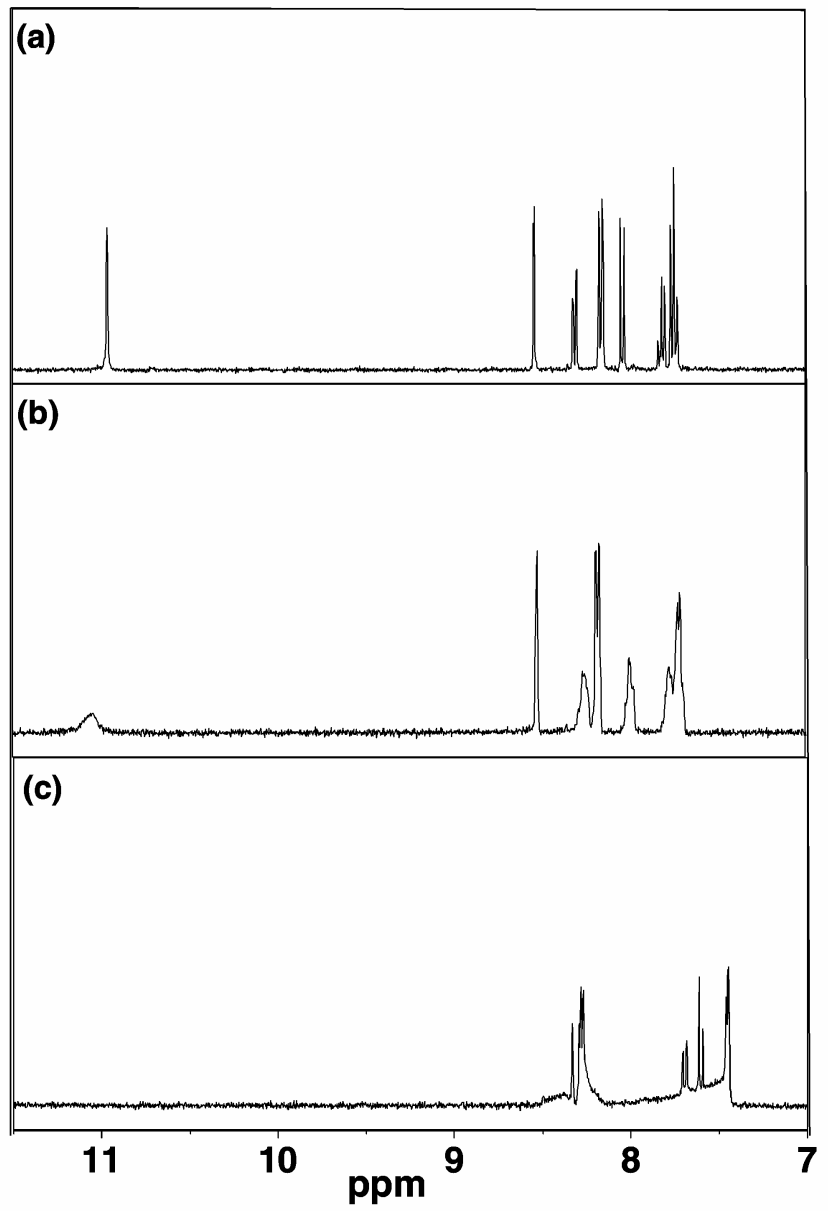

Figure 4. Proton NMR spectra of 1 in DMSO- $d_{6}$ in the presence of (a) 0 , (b) 5, and (c) 10 equivalents of TBAF. 
the formation of an anionic species, and not only allow dual mode of fluorescence signalling ('on-off' and 'off-on') depending on the choice of the monitoring wavelength, but more importantly, allow ratiometric signalling when the ratio of the fluorescence output at two different wavelengths is plotted as a

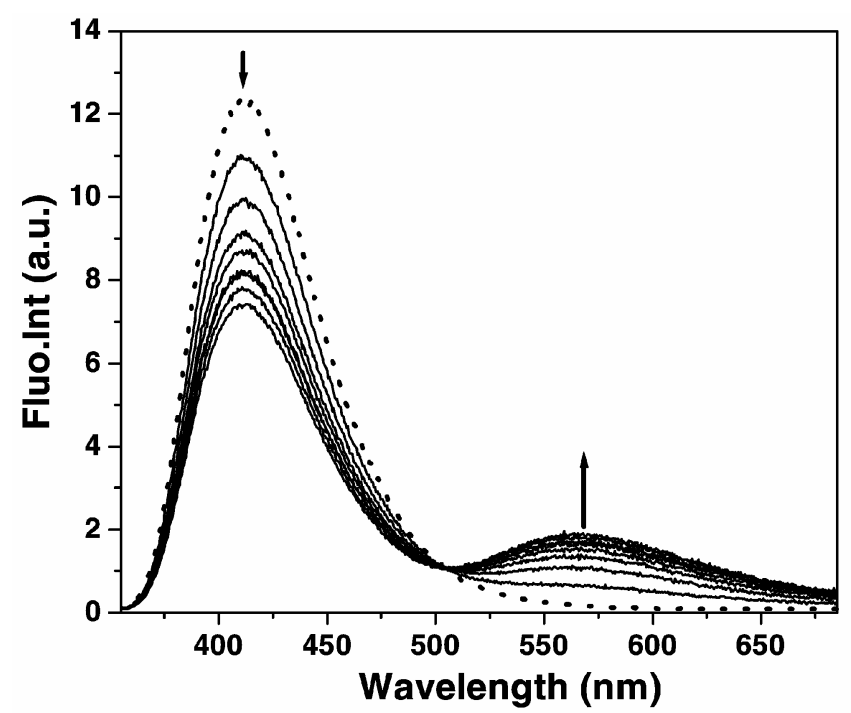

Figure 5. Fluorescence spectra of acetonitrile solution of $1\left(1.5 \times 10^{-6} \mathrm{M}\right)$ upon progressive addition of TBAF $\left(8.1 \times 10^{-6} \mathrm{M}\right.$ to $\left.4.4 \times 10^{-5} \mathrm{M}\right)$. The dotted curve represents the fluorescence spectrum of the free compound. $\lambda_{\mathrm{exc}}=350 \mathrm{~nm}$.

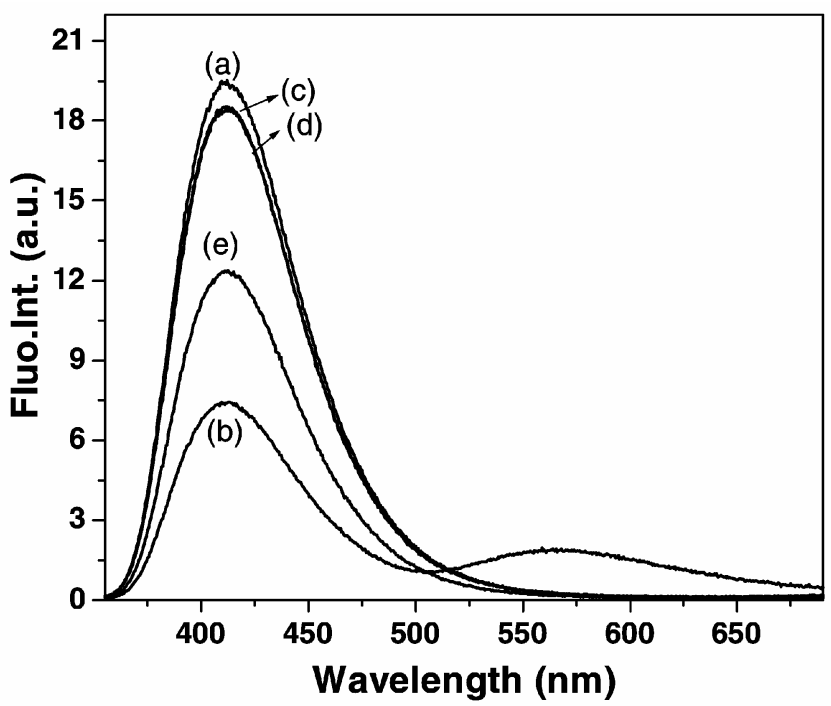

Figure 6. Fluorescence spectra of acetonitrile solution of $1\left(1.5 \times 10^{-6} \mathrm{M}\right)$ in the presence of halide anions: (a) with no added salt, (b) with fluoride $\left(4.4 \times 10^{-5} \mathrm{M}\right)$, (c) with chloride $\left(4.0 \times 10^{-3} \mathrm{M}\right)$, (d) with bromide $\left(4.0 \times 10^{-}\right.$ $\left.{ }^{3} \mathrm{M}\right)$ and $(\mathrm{e})$ with iodide $\left(4 \cdot 0 \times 10^{-3} \mathrm{M}\right) . \lambda_{\mathrm{exc}}=350 \mathrm{~nm}$. function of the concentration of $\mathrm{F}^{-}$. Figure 7 shows a plot of the ratio of the fluorescence intensities at 570 and $412 \mathrm{~nm}$ versus the concentration of $\mathrm{F}^{-}$. As can be seen, $I_{570} / I_{412}$ increases linearly with the concentration of fluoride ions in the concentration range studied.

\subsection{Computational study}

In order to further investigate whether the recognition process is mediated through the $\mathrm{H}$-bonding interaction between $\mathbf{1}$ and $\mathrm{F}^{-}$or proton abstraction from the amide hydrogen of 1 to $\mathrm{F}^{-}$, we have carried out DFT calculations. The system consisting of 1 and $\mathrm{F}^{-}$, with an initial $\mathrm{H}$... $\mathrm{F}$ distance set at around $1.75 \AA$ (as typical NH---F ${ }^{-}$hydrogen bond distance ranges between 1.73 and $1.77 \AA)^{43}$ and with $\mathrm{N}-\mathrm{H} \ldots \mathrm{F}$ linear geometry when optimised using the density functional method (at the B3LYP/STO-3G level

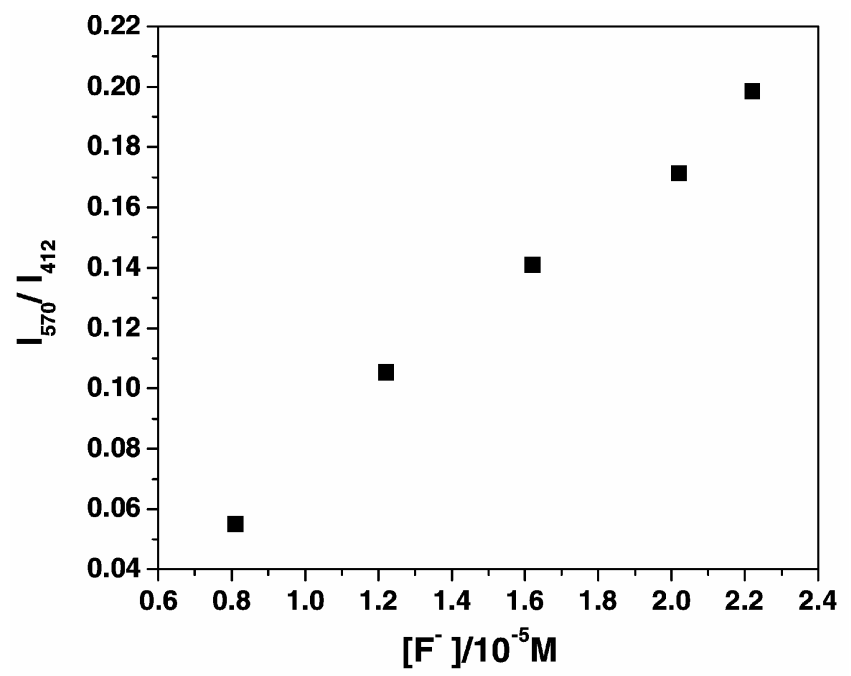

Figure 7. Ratiometric response $\left(I_{570} / I_{412}\right)$ of $\mathbf{1}(1.5 \times$ $\left.10^{-6} \mathrm{M}\right)$ in acetonitrile as a function of the concentration of $\mathrm{F}^{-}$.

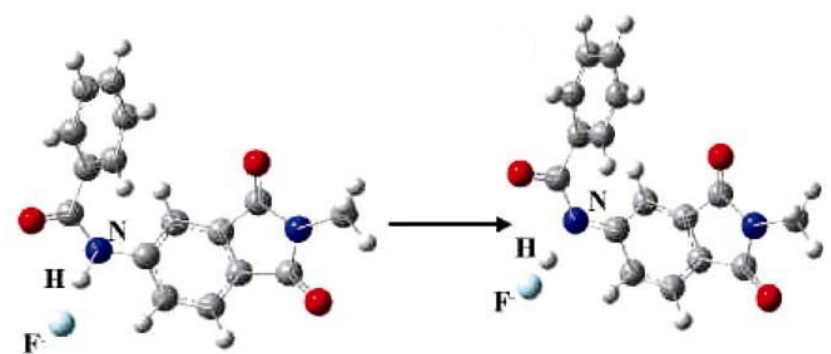

Figure 8. Geometries of the system before and after optimisation. The NH and HF distances in the optimised structure are 1.485 and $0.992 \AA$ respectively. 
Table 1. Theoretically calculated structural parameters ${ }^{a}$ of the receptor-halide ion systems.

\begin{tabular}{lcccc}
\hline System & $\mathrm{X}$ & $d(\mathrm{~N}-\mathrm{H})$ & $d(\mathrm{H} \cdots \mathrm{X})$ & $\alpha(\mathrm{NHX})$ \\
\hline $\mathbf{1} \ldots \mathrm{X}^{-}$ & $\mathrm{F}$ & 1.485 & 0.992 & $168 \cdot 180$ \\
& $\mathrm{Cl}$ & 1.223 & 1.635 & 171.972 \\
\hline
\end{tabular}

${ }^{\mathrm{a}}$ Bond lengths $(d)$ are in ångstroms and angles $(\alpha)$ are in degrees

using Gaussian 03 software $^{40}$ ) yielded a final geometry (figure 8) wherein the $\mathrm{H}-\mathrm{F}$ distance is $0.992 \AA$ and the N...H distance, $1.485 \AA$ (instead of a normal $\mathrm{N}-\mathrm{H}$ distance of $0.983 \AA$ ) suggesting deprotonation of the acidic imide hydrogen from 1 and formation of $\mathrm{HF}$.

Theoretical calculation has also been carried out with $\mathrm{Cl}^{-}$, which does not induce changes in the absorption and fluorescence properties of 1 . As expected, the optimised structure of the system corresponds to a hydrogen-bonded complex between 1 and $\mathrm{Cl}^{-}$(rather than formation of the anion of 1) with the $\mathrm{H}$... Cl distance of $1.63 \AA$ and $\mathrm{N}-\mathrm{H}$ distance of $1.2 \AA$. Since the gas phase $\mathrm{HCl}$ and $\mathrm{HF}$ distances are $1.274 \AA$ and $1.01 \AA$, it is evident that H-bonding interaction between 1 and $\mathrm{Cl}^{-}$leads to elongation of both the distances. The $\mathrm{N} \ldots \mathrm{H} \ldots \mathrm{Cl}$ angle is found to be $171.97^{\circ}$. The calculated structural parameters of the receptor-halide complexes are collected in table 1.

\section{Conclusions}

It is shown that 4-benzoylamido-N-methylphthalimide acts both as a colourimetric sensor and a ratiometric fluorescence sensor for $\mathrm{F}^{-}$in acetonitrile. The marked changes in the electronic absorption and fluorescence response of the sensor system upon addition of the fluoride ion can even be observed with the naked eye. Since other halide ions, $\mathrm{Cl}^{-}, \mathrm{Br}^{-}$and $\mathrm{I}^{-}$, hardly induce any change in the absorption or fluorescence behaviour of the system, the signalling is specific for $\mathrm{F}^{-}$. Experimental and theoretical results establish unequivocally that $\mathrm{F}^{-}$-induced intermolecular proton transfer is responsible for the sensory action of the system. This specificity of the sensor system towards $\mathrm{F}^{-}$is clearly due to its much higher electronegativity as compared to the other halides. We stress however that this signalling study has been carried out in a nonaqueous medium, acetonitrile. In aqueous solution, since the water molecules compete with the $\mathrm{F}^{-}$for hydrogen-bonding interac- tion with the acidic hydrogen of the sensor system, we hardly observe any change of the absorption and fluorescence behaviour of the system. Work is underway to develop polymer-supported sensor utilizing the same receptor unit for practical purposes.

\section{Acknowledgements}

This work is supported by the Department of Science and Technology, Government of India and the UPE Program of the University Grants Commission (UGC). MS and BB thank the Council of Scientific and Industrial Research, New Delhi and RK thanks UGC for fellowships.

\section{References}

1. Beer P D and Cadman J 2000 Coord. Chem. Rev. 205 131

2. Schmidtchen F P and Berger M 1997 Chem. Rev. 97 1609

3. Gale P A 2001 Coord. Chem. Rev. 21379

4. Davis A P and Wareham R S 1999 Angew. Chem., Int. Ed. 382978

5. Martinez-Manez R and Sancenon F 2003 Chem. Rev. 1034419

6. Sukasai C and Tuntulani T 2003 Chem. Soc. Rev. 32 192

7. Lee D H, Lee H Y and Hong J-I 2002 Tetrahedron Lett. 437273

8. Gale P A 2000 Coord. Chem. Rev. 199181

9. Amendola V, Gomez D E, Fabrizi L and Licchelli M 2006 Acc. Chem. Res. 39343

10. Pordi L, Bolletta F, Montalti $\mathrm{M}$ and Zaccheroni N 2000 Coord. Chem. Rev. 199181

11. Valeur B and Leray I 2000 Coord. Chem. Rev. 2053

12. de Silva A P, Fox D B, Huxley A J M and Moody T S 2000 Coord. Chem. Rev. 20541

13. Rurack K 2001 Spectrochim. Acta A57 2161

14. Keefe M H, Benkstein K D and Hupp J T 2000 Coord. Chem. Rev. 205201

15. Robertson A and Shinkai S 2000 Coord. Chem. Rev. 205157

16. de Silva A P and Tecilla P (eds) 2005 Special issue on fluorescent sensors. J. Mater. Chem. 15265

17. Ramachandram B and Samanta A 1997 Chem. Commun 1037

18. Sankaran N B, Banthia S, Das A and Samanta A 2002 New J. Chem. 261529

19. Banthia S and Samanta A 2002 J. Phys. Chem. B106 5572

20. Banthia S, Sarkar M and Samanta A 2005 Res. Chem. Intermed. 3125

21. Banthia S and Samanta A 2006 J. Phys. Chem. B110 6437

22. Kirk K L 1991 Biochemistry of the halogens and inorganic halides (New York: Plenum) p. 58 
23. Kleerekoper M 1998 Endocrinol. Metab. Clin. North Am. 27441

24. Wiseman A 1970 Handbook of experimental pharmacology (Berlin: Springer-Verleg) vol. 20, part 2, p. 48

25. Ghosh T, Maiya B G and Wong M W 2004 J. Phys. Chem. A108 11249

26. Gunnlaugsson T, Kruger P E, Lee T C, Prakesh R, Pfeffer F M and Hussey G M 2003 Tetrahodron Lett. 446575

27. Chen Q and Chen C 2004 Tetrahedron Lett. 456493

28. Coskun A and Akkaya E 2004 Tetrahedron Lett. 45 4947

29. Gale P, Sessler J L and Vladimir K 1998 Chem. Commun. 1

30. Biocchi M, Boca L D, Gomez D E, Fabbrizzi L, Liccheli M and Monazani E $2004 \mathrm{~J}$. Am. Chem. Soc. 126 16507

31. Jose D A, Kumar D K, Ganguly B and Das A 2004 Org. Lett. 63445

32. Jose D A, Kumar D K, Ganguly B and Das A 2005 Tetrahedron Lett. 465343
33. Ding J and Day M 2006 Macromolecules 396054

34. Arimori S, Davidson M G, Fyles T M, Hibberet T G, James T D and Kociok-Köhn 2004 Chem. Commun. 1640

35. Ren J, Wang Q, Qu D, Zhao X and Tian H 2004 Chem. Lett. 33974

36. Xu G and Tarr M A 2004 Chem. Commun. 1050

37. Kovalchuk A, Bricks J L, Reck G, Rurack K, Schulz B, Szumna A and WeiBhoff H 2004 Chem. Commun. 1946

38. Liu B and Tian H 2005 J. Mater. Chem. 152681

39. Soujanya T, Fessenden R W and Samanta A $1996 J$. Phys. Chem. 1003507

40. Frish M J et al 2003 Gaussian 03 Revision B-05 Gaussian Inc. Pittsburgh, PA

41. This value is lower than that obtained using AM1 calculation. See for example, ref. [39]

42. The fluorescence profile of the new band is characterized by single exponential decay with a lifetime of $1.9 \mathrm{~ns}$

43. Brooks S J, Evans L S, Gale P A and Hursthouse M B 2004 Chem. Commun. 734 